\title{
Metástasis intestinales yeyunales, forma de presentación de un carcinoma pulmonar
}

\section{Jejunal intestinal metastases, a form of presentation of pulmonary carcinoma}

\author{
D. Ruiz-Clavijo García ${ }^{1}$, J. Eguaras Ros ${ }^{1}$, BM. González de la Higuera Carnicer ${ }^{1}$, \\ E. Albéniz Arbizu ${ }^{1}$, JJ. Vila Costas ${ }^{1}$, F. Jiménez Bermejo ${ }^{2}$
}

\section{RESUMEN}

Los tumores primarios de intestino delgado son muy infrecuentes, siendo todavía más raros los metastásicos. Es excepcional que las metástasis de intestino delgado se manifiesten antes que el tumor primario. La presentación clínica puede requerir una resección quirúrgica intestinal motivada por perforación, hemorragia, obstrucción-suboclusión intestinal e incluso invaginación intestinal. La supervivencia, es escasa y generalmente no supera las 20 semanas, independientemente del tratamiento que se realice.

Palabras clave. Metástasis yeyunales. Cáncer de pulmón. Anemia ferropénica.

\begin{abstract}
Primary tumors of the small intestine are rare, and metastatic ones are even rarer. It is exceptional for small bowel metastases to manifest before the primary tumor. The clinical presentation may require surgical resection motivated by intestinal perforation, hemorrhage or intestinal obstruction-subocclusion. Survival is scarce and generally does not exceed 20 weeks, regardless of the treatment performed.
\end{abstract}

Keywords. Jejunal metastasis. Lung cancer. Iron deficiency anemia.
1. Complejo Hospitalario de Navarra. Servicio de Digestivo. Pamplona

2. Complejo Hospitalario de Navarra. Servicio de Medicina Interna. Pamplona

Recepción: 26 de agosto de 2014

Aceptación provisional: 10 de noviembre de 2014

Aceptación definitiva: 15 de diciembre de 2014

\section{Correspondencia:}

David Ruiz-Clavijo García

Complejo Hospitalario de Navarra

C/ Irunlarrea, 4

31008 Pamplona. Navarra

E-mail: davidruizcla@gmail.com 


\section{INTRODUCCIÓN}

El carcinoma primitivo de pulmón es la causa de muerte más frecuente por neoplasia en varones en los países occidentales. Alrededor de la mitad de los casos presentan metástasis en el momento del diagnóstico, siendo más frecuentes en cerebro, hueso, hígado, suprarrenales y ganglios linfático ${ }^{1}$. El esófago, por extensión directa, es la región del tubo digestivo que más se afecta, mientras que las metástasis del intestino delgado, aunque raras, son más comunes de lo que se pensó en un principio.

Las metástasis de intestino delgado en el carcinoma primitivo de pulmón son excepcionales y sus manifestaciones clínicas raras $^{2}$. Cuando éstas se producen, pueden causar hemorragia, malabsorción, perforación intestinal, o incluso invaginación intestinal ${ }^{3,4}$ aunque la forma más frecuente de presentación es la suboclusiónobstrucción intestinal ${ }^{5}$. Ante la presencia de una anemia ferropénica en un paciente con cáncer de pulmón no debemos olvidar las metástasis intestinales como una de las posibles causas de la hemorragia.

\section{CASO CLÍNICO}

Mujer de 83 años de edad con factores de riesgo vascular (hipertensión y dislipemia). Entre sus antecedentes destacaban: diverticulosis de colon y pólipos adenomatosos tubulares. Había sido intervenida de amígdalas, apéndice y de eventración abdominal. Como antecedente familiar destacaba su hija fallecida a los 52 años de cáncer gástrico.

Acudió al servicio de Urgencias por un cuadro de un mes de evolución de dolor abdominal persistente en hemiabdomen superior y región periumbilical de predominio postprandial, asociado a nauseas sin vómitos. La paciente presentaba un ritmo intestinal con tendencia al estreñimiento exacerbado durante dicho periodo. Presentaba además anorexia y pérdida ponderal de $7 \mathrm{~kg}$.

Estaba en tratamiento con: artilog $200 \mathrm{mg}$

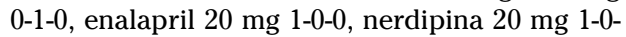
1 , pantoprazol $40 \mathrm{mg} 1-0-0$, simvastatina $10 \mathrm{mg}$ $0-0-1$, y venlafaxina $75 \mathrm{mg} 0-0-1$.

A la exploración física presentaba: tensión arterial: 120/80; frecuencia cardiaca: 81 latidos/ min. Afebril. Regular estado general. Bien hidratada y ligera palidez mucocutánea. Nódulo supraclavicular izquierdo, duro a la palpación, mó- vil, no doloroso. Auscultación cardiaca normal. Auscultación pulmonar sin hallazgos. Abdomen blando, depresible, doloroso a la palpación profunda en hemiabdomen superior y periumbilical, sin masas ni megalias, peristaltismo disminuido. Extremidades inferiores sin edemas ni signos de trombosis venosa profunda.

En las exploraciones complementarias: radiología de tórax: nódulo pulmonar de $2 \mathrm{~cm}$ en LSD. ECG: ritmo sinusal a 86 latidos/min. Analítica de sangre: anemia microcítica (Hb: $10 \mathrm{~g} / \mathrm{dl}$ (11,9-16,5), VCM: 77,4 (80,2-99,4). Leucocitosis con neutrofilia (20.000 leucocitos/ml $(3,5-10,5)$ con $84 \%$ de neutrófilos (37-73). VSG $67 \mathrm{~mm} / \mathrm{h}$ (210). PCR $150 \mathrm{mg} / \mathrm{l}(0-10)$.

Se completó el estudio analítico con perfil férrico completo: hierro sérico $14 \mu \mathrm{g} / \mathrm{dl}(37-145 \mu \mathrm{g} /$ dl), índice de saturación de transferrina 15\% (20$50 \%$ ) y ferritina $463 \mathrm{ng} / \mathrm{ml}$ (valores $<30 \mathrm{ng} / \mathrm{ml}$ implica ferropenia). También se determinó antígeno carcinoembrionario (CEA) pensando en neoplasias malignas gastrointestinales y anticuerpos anti-transglutaminasa siendo sus valores normales.

Ante la persistencia del dolor abdominal que requería de opiáceos intravenosos se realizó una ecografía abdominal donde se observaron adenopatías mesentéricas de tamaño patológico, completándose el estudio con tomografia axial computarizada (TAC) abdomino-pélvica.

En dicha TAC se observó un engrosamiento mural de un segmento de intestino delgado proximal de unos $4,4 \mathrm{~cm}$ de diámetro que se acompañaba de múltiples adenopatías mesentéricas con centro hipodenso.

Se realizó una enteroscopia anterógrada donde se observaba a nivel de ángulo de Treitz, formación polipoidea con ulceración de unos 15 $\mathrm{mm}$ de diámetro, de la que se tomaron biopsias. Se introdujo el endoscopio hasta yeyuno proximal (50-60 $\mathrm{cm}$ distales a píloro) y se tomaron biopsias de una neoformación ulcerada, rígida y friable, de unos $4 \mathrm{~cm}$ de diámetro y que ocupaba la mitad de la circunferencia, de unos $4 \mathrm{~cm}$ de diámetro, que no impidió el paso del endoscopio. A unos $30 \mathrm{~cm}$ de píloro se observó otra zona ulcerada, rígida, de unos $2 \mathrm{cms}$ de diámetro que se biopsió (C). (Fig. 1).

El análisis histológico fue compatible con metástasis yeyunales de carcinoma pobremente diferenciado. Tanto la morfología como el inmunofenotipo fueron compatibles con carcinoma de células grandes de pulmón.

Inmunofenotipo: citoqueratinas AE1-AE3: (+); S100, HMB 45: (-); citoqueratina 20: (-), citoqueratina 7 : $(+)$; TTF1: (-); napsina: $(-)$; vimentina: (+); p63: (+); cd10: (-); WT1: (-) ; GCDFP 15: $(-)$; citoqueratina 19: (+); citoqueratina 5-6: (-), citoqueratina 34 beta 12; CDX2: (-). 


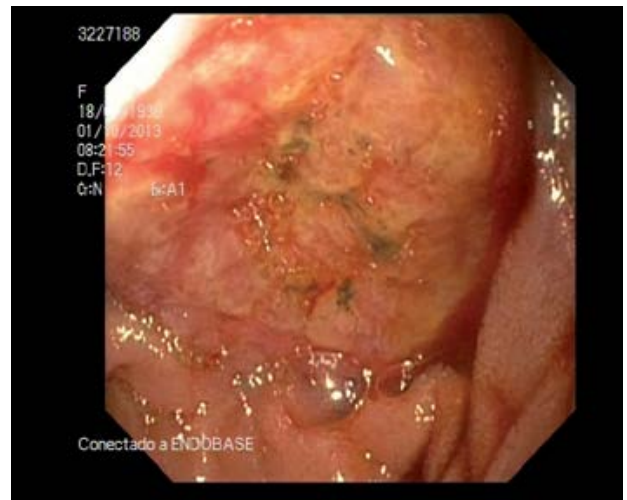

Figura 1. Neoformación ulcera rígida y friable.

Se completó el estudio con TAC torácico donde se observó un nódulo pulmonar sólido de aspecto espiculado en apex derecho de $2,6 \mathrm{~cm}$, de contacto pleural; adenopatías mediastínicas en el compartimento paratraqueal superiores e inferiores y pretraqueales, hiliares derechas y a nivel de la bifurcación bronquial. Adenopatías supraclaviculares bilaterales (Fig. 2).

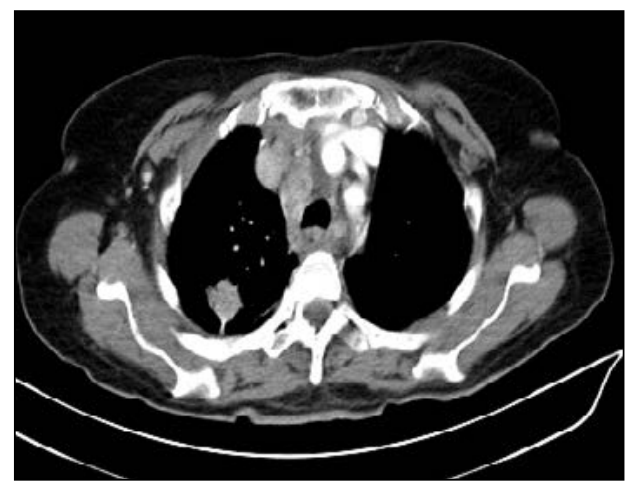

Figura 2. Nódulo pulmonar espiculado.

Dada la edad de la paciente y el estadio avanzado de la enfermedad y la presentación un ECOG 3 se decidió tratamiento paliativo, falleciendo la paciente a los 22 días de su alta hospitalaria.

\section{DISCUSIÓN}

Los tumores malignos del intestino delgado son infrecuentes, estimándose su incidencia entre el 1 y el $6 \%$ del total de las neoplasias gastrointestinales ${ }^{6}$. La mayoría son tumores primarios malignos, como el adenocarcinoma y los tumores del estroma gastrointestinal (gastrointestinal stromal tumors, GIST). Son excepcionales los tumores metastásicos ( 1 a $4 \%$ en las series de autopsias).

Se planteó el diagnóstico diferencial entre neoplasia, enfermedad inflamatoria intestinal tipo Crohn o una posible enfermedad celiaca, y la posibilidad de cuadro infeccioso como una enfermedad de Whipple o tuberculosis intestinal. La sospecha de neoplasia tanto primaria (adenocarcinoma) como metastásica (melanoma, pulmón o colon como opciones más frecuentes) a nivel de intestino delgado era muy rara. Por otro lado la presentación de una enfermedad de Crohn a la edad de la paciente, a dicho nivel de intestino delgado y sin diarrea nos parecía un diagnóstico muy remoto. La posibilidad de una enfermedad celiaca con presentación atípica en yeyuno y con adenopatías mesentéricas también resultaba improbable. La etiología infecciosa pensando en una enfermedad de Whipple sin diarrea y sin artralgias igualmente parecía incierta. Para terminar la sospecha de tuberculosis intestinal donde el dolor abdominal es el síntoma más frecuente asociado a pérdida de peso (en $1 / 3$ de los casos) a pesar de que nuestro paciente no presentaba fiebre (ocurre hasta en el $50 \%$ de los pacientes) era una sospecha también dudosa por la localización.

Las metástasis más frecuentes en intestino delgado son de melanoma maligno, cáncer de pulmón y cáncer de colon? ${ }^{7}$. Otras metástasis menos frecuentes son las de cáncer de mama, riñón, cérvix, ovario y osteosarcoma. En el trabajo de Antler y col${ }^{8}$ se describe que el cáncer de pulmón indiferenciado de células grandes y de células pequeñas produce metástasis más frecuentemente que otros tipos histológicos, mientras que McNeill y $\mathrm{col}^{9}$ afirman que las metástasis son más frecuentes en los carcinomas pulmonares escamosos ${ }^{8-9}$. Excepcionalmente, las metástasis intestinales se manifiestan previamente al tumor pulmonar primario. La localización más habitual suele ser el yeyuno, el íleon o ambos y, en menor grado, el duodeno. Inicialmente se 
presentan por dolor abdominal, secundario a perforación u obstrucción intestinal, o hemorragia digestiva ${ }^{10}$. En nuestro caso, la lesión pulmonar se diagnosticó después de los síntomas digestivos debido a un cuadro de dolor abdominal y clínica suboclusiva junto con una anemia ferropénica moderada, lo cual llevó a realizar inicialmente una tomografía axial computarizada y dado sus hallazgos se planteó una enteroscopia diagnóstica que fue efectiva y diagnóstica.

En las metástasis intestinales sintomáticas, el tratamiento de elección es la resección quirúrgica como paliación de la enfermedad $^{11}$. Las metástasis intestinales representan un estadio avanzado de la enfermedad y condicionan un peor pronóstico, con una supervivencia global no superior a 4 meses $^{12}$. Sin embargo, en algunas series de pacientes seleccionados (cirugía previa del tumor primario, metástasis únicas) donde las metástasis de intestino delgado se han resecado, los pacientes han presentado una supervivencia superior (de 6 a 8 meses) y hay algún caso de supervivencia prolongada. Además, según una de las series más extensas estudiadas, la complicación de las lesiones del intestino delgado no es infrecuente (hasta un $30 \%$ ), por tanto, el manejo quirúrgico precoz de estas lesiones puede contribuir a aumentar la supervivencia de pacientes seleccionados (poca carga tumoral, buen estado general) y puede evitar sus graves complicaciones $^{13}$. Asimismo, la cirugía semielectiva en pacientes con síntomas de hemorragia u obstrucción con metástasis intestinales diagnosticadas podría contribuir a la mayor supervivencia de estos pacientes. Con el uso habitual de la PET en la estadificación del cáncer de pulmón, el diagnóstico de metástasis intestinales asintomáticas irá en aumento, por lo que las decisiones terapéuticas deberán contemplar los aspectos previamente referidos.

\section{BIBLIOGRAFÍA}

1. Hsing CT, Kim HY, Lee JH, Han JS, LeE JH, Chang JS et al. Gastrointestinal metastasis from a primary adenocarcinoma of the lung pre- senting with acute abdominal pain. Korean $\mathrm{J}$ Gastroenterol 2012; 59: 382-385.

2. Mehta RS, Liman AD, Passero VA, Liman AK. Lung cancer with gastrointestinal metastasis - review of theories of metastasis with three rare case descriptions. Cancer Microenviron 2013; 6: 203-211.

3. Sasada S, Ukon K, Sato Y, Okusaki K. A case of metastatic small intestinal tumor from primary lung cancer with hemorrhage and a high G-CSF serum level. Gan To Kagaku Ryoho 2013 ; 40: 777-780.

4. De Miguel Valencia M, Esquiroz Lizaur I, Marzo Virto J, De Miguel Velasco M, Yagüe Hernando A. Intestinal intussusception as the first manifestation of lung cáncer. An Sist Sanit Navar 2014; 37: 299-304.

5. Tanaka T, Minami $S$, Tsutsumi R, Azuma T, Matsuo $\mathrm{S}, \mathrm{AbE} \mathrm{K}$ et al. A metastatic jejunal tumor from squamous cell carcinoma of the lung found in an intestinal perforation. Case Rep Gastroenterol 2011; 5:636-641.

6. Gill SS, Heuman DM, Mihas AA. Small intestinal neoplasms. J Clin Gastroenterol 2001; 33: 267-282.

7. Bugiantella W, Cavazzoni E, Graziosi L, Valiani S, Franceschini MS, Donini A. Small bowel metastasis from lung cancer: a possible cause of acute abdomen. Case report and literature review. G Chir 2011; 32: 120-122.

8. Antler As, Ough Y, Pitchumoni CS, Davidian M, Thelmo W. Gastrointestinal metastasis from malignant tumors of the lung. Cancer 1982; 49: 170-172.

9. McNeill PM, Wagman LD, Neifeld JP. Small bowel metastasis from primary carcinoma of the lung. Cancer 1987; 59: 1486-1489.

10. Garwood RA, SaWyer MD, Ledesma EJ, Foley E, Claridge JA. A case and review of bowel perforation secondary to metastatic lung cancer. Am Surg 2005; 71:110-116. Review.

11. Berger A, Cellier C, Daniel C, Kron C, Riquet M, BARBIER JP et al. Small bowel metastases from primary carcinoma of the lung: clinical findings and outcome. Am J Gastroenterol 1999; 94:1884-1887.

12. Garwood RA, Sawyer MD, Ledesma EJ, Foley E, Claridge JA. A case and review of bowel perforation secondary to metastatic lung cancer. Am Surg 2005; 71: 110-116.

13. Goh BK, Yeo AW, Koong HN, Ool LL, Wong WK. Laparotomy for acute complications of gastrointestinal metastases from lung cancer: Is it a worthwhile or futile effort? Surg Today 2007; 37: 370-374. 